\title{
DINAMIKA ARSITEKTUR INDONESIA DAN REPRESENTASI 'POLITIK IDENTITAS’ PASCA REFORMASI
}

\author{
Kemas Ridwan Kurniawan \\ Departemen Arsitektur, Fakultas Teknik, Universitas Indonesia, Kampus UI Depok, 16424 \\ kemas.ridwan@gmail.com
}

\begin{abstract}
ABSTRAK. Menguatnya politik identitas di Indonesia pasca reformasi telah melahirkan formasi arsitektur baru yang tersebar di berbagai daerah di Indonesia. Identitas budaya terkait indigenitas menjadi bagian dari politik identitas yang menurut sebagian pengamat politik disinyalir dimanfaatkan para elit dan penguasa untuk kepentingan politik kekuasaan. Ironisnya, dalam bidang arsitektur, definisi tentang identitas ini justru semakin tidak jelas. Definisi-definisi ini berputar pada debat tentang pencarian jati diri yang tidak pernah selesai dan sering diasosiasikan dengan proses untuk memunculkan jati diri kebudayaan sebagai jawaban atas tantangan universalitas arsitektur modern, globalisasi dan kemajuan teknologi.
\end{abstract}

Makalah ini mencoba mengambil dari sudut pandang yang berbeda yaitu politik identitas dalam silangannya dengan arsitektur ('space'), waktu (sejarah) dan aspek sosial-politik. Isu yang muncul adalah bagaimana politik identitas perlahan-lahan melanjutkan pengaruhnya dalam formasi arsitektur di Indonesia pasca reformasi, di balik kesalah-pahaman tentang definisi 'identitas' dalam debat-debat arsitektur di Indonesia. Hal ini terjadi karena banyak arsitek atau teoretikus arsitektur di Indonesia membatasi dirinya hanya dalam lingkup arsitektur, dan gagal berinteraksi secara lebih luas dengan isu-isu sosio politik. Konsekuensinya, di satu sisi, istilah 'identitas' kehilangan pengaruh sosiopolitiknya dan direduksi kepada masalah-masalah estetika visual semata, yang mengaburkan identitas arsitektur sebagai suatu konsep sosial budaya. Sementara itu, di sisi lain pemanfaatan identitas sebagai bagian dari komoditas politik juga melanjutkan dinamika yang terjadi di daerah (regional) yaitu warna kekuasaan (power) dalam formasi arsitektur di Indonesia sebagai imbas dari Desentralisasi. Makalah ini mengkritisi perilaku politik identitas yang cenderung berubah menjadi 'regime' dalam formasi identitas arsitektur saat ini, dan kurang terangkatnya isu identitas arsitektur dengan dinamika sosio-politik dan keseharian ('everyday-life') masyarakat.

Kata Kunci: subjektivitas, hibrid, indigenitas, pasca-nasionalisme

ABSTRACT. Straighthening the politics of identity in Indonesia after the 1997 political reformation has increased the formation of new architecture which are scattered in various regions in Indonesia. The cultural identity on indigeneity and become part of identity politics. It was exploited by elites and rulers for the sake of power politics. Ironically, in the field of architecture, the definition of this identity is even more unclear. These definitions spin on the debate about the search for identity that was never finished and is often associated with the process to bring a cultural identity as a response to the challenges of modern architecture such as universality, globalization and technological progress.

This paper tried to look at architecture (space) in the intersection with time (history) and socio-political aspects. The issue that arises is how the politics of identity is slowly continuing influence in the formation of architecture in Indonesia after the 1997 political reform, under misconceptions about the definition of 'identity' in debates of architecture in Indonesia. This happens because many architects or architectural theorists in Indonesia restricts itself only in the sphere of architecture, and failed to interact more broadly with social and political issues. Consequently, on the one hand, the term 'identity' loss of the socio-political influences and are reduced to a visual aesthetic problems alone, which obscure the identity of architecture as a socio-cultural concept. Meanwhile, on the other hand the use of identity as part of a political commodity also continue the dynamics that occur in the area (regional) is the color of power (power) in the formation of architecture in Indonesia as the impact of decentralization. The paper criticized the behavior of identity politics that tends to turn into a 'regime' in the current architectural identity formation, and less lifting of architecture with issues of identity and everyday social and political dynamics ( 'everyday-life') of community.

Keywords: subjectivity, hybrid, indigeneity, post-nationalism 


\section{PENDAHULUAN}

Indonesia untuk pertama kali berpartisipasi di dalam Pameran internasional Arsitektur Venice Biennale pada tahun 2014. Indonesia menampilkan kritik Arsitektur Indonesia dalam hubungannya dengan representasi, identitas dan politik. (Gambar 1). [24]

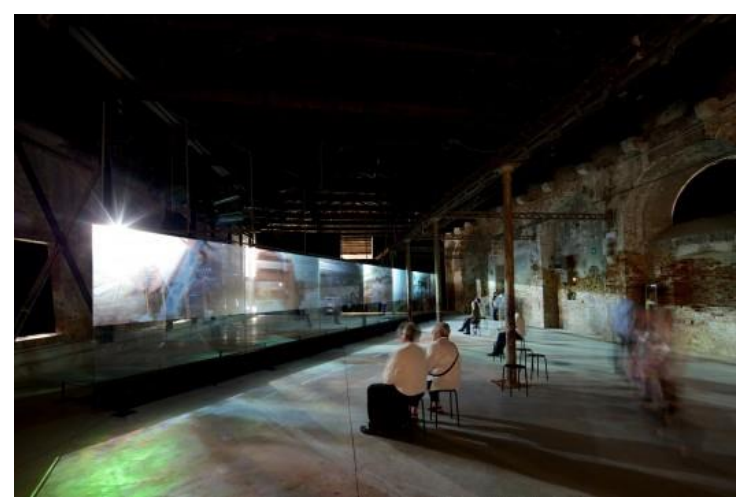

Gambar 1. Paviliun Indonesia pertama pada Venice Biennale 2014.

(Sumber: Nico Saleh@

http://www.archdaily.com/527548/craftsmanshipmaterial-consciousness-inside-indonesia-s-pavilionat-venice-biennale-2014/)

Hal yang menarik adalah representasi di balik citra bergerak yang hadir melalui sorotan cahaya lensa yang memproyeksikan gambar pada panel-panel kaca berjajar dengan posisi miring terhadap aksis ruang pameran. Pengunjung dapat melihat gambar-gambar bergerak ini dari kedua sisi. Berkaca pada paviliun Hindia Belanda pada berbagai International Colonial Exposition di Eropa sebelum PD II [5], tentunya Paviliun Indonesia di Venice Biennale ini sangat jauh berbeda. Penggunaan teknik menyorotkan gambar pada media kaca menjadi salah satu taktik menarik, karena menyebabkan estetika craftsmanship kehilangan dimensi 'crafting' yang kuat sisi sosialnya. Media kaca merepresentasikan abstraksi yang merupakan bayangan 'maya' akibat pantulan (refleksi yang dihadirkan).

Terlepas dari kekurangan yang ada, tentunya kehadiran paviliun Indonesia pertama tersebut berhasil membuka jalan perkenalan arsitektur Indonesia ke ranah internasional. Pengakuan Sopandi tentang 'kegugupan' [28] menarik disimak karena menyiratkan kegamangan dalam merepresentasikan arsitektur Indonesia. Persoalannya bukan pada modernitas dan representasi identitas arsitektur di Indonesia tapi bagaimana strategi dan politik menampilkan identitas itu sendiri dengan absennya realitas sosial yang sesungguhnya.
Politik identitas banyak mewarnai dinamika perjalanan arsitektur di Indonesia. Sebagai contoh, di zaman Orde Baru, bentuk-bentuk bangunan modern yang berpadu-padan dengan arsitektur Jawa secara seragam (Jawanisasi) sempat mewarnai arsitektur dan menjadi suatu tradisi baru pada masa itu di Indonesia. Contoh lain adalah pemakaian warna kuning (kuningisasi), yang menjadi warna resmi ruang publik di berbagai daerah di Indonesia, menyiratkan nuansa politik arsitektur regime Orde Baru. Dalam hal ini, ruang ('space') yang terjadi adalah akibat hubungan sosial-politik era tersebut, sementara aspek keruangan (spasialitas) yang muncul adalah lebih personal (kepentingan kelompok tertentu) dan cenderung politikal [9 : 225].

Sinyal adanya perubahan dalam arsitektur modern pascakolonial dan pasca reformasi dapat diamati dari fenomena terjadinya 'violence', instabilitas, perpecahan, chaos, dan gangguan extrim yang terjadi sepanjang periode transisi era pasca reformasi yang menggambarkan suatu paradox modernitas.

Makalah ini diawali oleh rasa tidak nyaman penulis mengenai pertanyaan klasik yang sering muncul dalam berbagai media Arsitektur di Indonesia seperti 'Mencari Identitas Arsitektur Indonesia', 'Mana Identitas Arsitektur Kita?', 'Apakah Arsitektur Indonesia itu Ada? Pertanyaan seperti ini, di satu sisi bisa menjadi tantangan para arsitek dalam proses kreatifnya, namun di sisi lain dapat menjadi belenggu yang menyesatkan dan keluar dari akar permasalahan yang sesungguhnya terkait aspek sosial budaya yang lebih luas. Hal ini terjadi karena identitas hanya dipahami secara literal dan cenderung visual fisik (estetika kasat-mata).

Makalah ini menelusuri politik identitas yang kental muncul dan mewarnai Arsitektur modern di Indonesia yang bersaling-silang dalam ruang-waktu. Identitas menjadi media/alat dan direduksi untuk kepentingan politik tertentu. Politik Identitas justru sangat kental membentuk formasi arsitektur modern di Indonesia di balik wacana konstruksi identitas itu sendiri bahkan hingga pasca reformasi. Meminjam istilah produksi ruang dari Lefebvre [16], identitas juga diproduksi dan bukan hanya dikonstruksi-kan. 


\section{METODE PENELITIAN}

Penelitian ini mengandalkan data yang di peroleh melalui kajian literatur, baik yang bersifat teori maupun data terkait arsitektur keIndonesiaan. Kajian teori difokuskan pada upaya meletakkan dasar pemahaman tentang arsitektur, politik identitas dan representasinya. Sementara itu untuk mengkritisi fenomena arsitektur Indonesia, penelitian ini mencoba melihat dari aspek sosial politik yang mungkin masih dianggap sedikit tabu untuk dilakukan. Persinggungan antara ruang, waktu dan situasi geopolitik di Indonesia sedikit banyak membantu memunculkan periodisasi baru pasca reformasi seperti pos-nasionalisme, etno-nasionalisme, dan kondisi hypercomplexity, yang tentunya membuka wacana baru untuk diperdebatkan kembali. Era pasca reformasi di Indonesia adalah era yang menarik untuk disimak sekaligus juga memunculkan tantangan baru sebagai sebuah tulisan sejarah karena dianggap masih belum terlalu lama berlalu. Oleh karena itu, tulisan ini lebih banyak mengajak pembaca untuk memikirkan ulang tentang apa itu identitas arsitektur di Indonesia agar tidak terjebak pada sinkretisme semata.

Alur penelitian dimulai dengan kajian atas terminologi identitas, politik dan representasi, istilah-istilah yang selalu menjadi perdebatan dalam wacana Arsitektur di Indonesia. Selanjutnya penelitian mulai mencoba melihat konteks arsitektur Indonesia pasca reformasi dan kaitannya dengan aspek sosial dan geopolitik di Indonesia. Bagian ini sekaligus memetakan berbagai pemikiran para sejarahwan arsitektur. Tahap selanjutnya adalah filterisasi yaitu dengan melihat dinamika politik versus arsitektur yang memperlihatkan Ekses sebagai suatu Tantangan, dan mengerucut pada upaya memikirkan kembali apa itu Identitas Arsitektur Indonesia pasca reformasi.

\section{HASIL DAN PEMBAHASAN}

\section{Terminologi}

Istilah Identitas memuat konotasi yang berbeda-beda tergantung konteks. Dalam aspek humaniora dan sosial, menurut du Gay dkk, 'Identity' has achieved its contemporary centrality both theoretically and substantively, because that to which it is held to refer whether the 'it' in question is, for example, the category 'man', 'black', 'work', 'nation', or 'community' - is regarded in some sense as being more contingent, fragile and incomplete and thus more amenable to reconstitution than was previously thought possible.' [4]

Dalam kritik terhadap pemahaman para 'essensialis' mengenai 'gender difference', Jane Rendell, seorang Kritikus Arsitektur sekaligus Feminis yang juga mengajar di the Bartlett UK menyampaikan bahwa the feminine is not only biological but also cultural, and has been associated with the other and with lack (following Jacques Lacan), and as the site of difference itself (Jacques Derrida).' [2]. Hal ini menurut Rendell karena 'Identities are contingent and situated, constructed in response to particular times and places' [2]. Oleh karena itu, kita dapat memahami bahwa identitas adalah suatu 'proses' budaya yang tidak pernah berhenti ('incomplete'), dan bukan seperti sebuah monumen statis atau artefak. Identitas juga tertentu dan situasional. Dengan demikian selain artefak fisik (bangunan, monumen dan lain-lain), identitas mesti melekat dengan dinamika aspek sosial budaya yang menyatu di dalamnya.

Identitas diibaratkan seperti retakan, jeda, bekuan atas suatu proses yang terjadi dalam suatu spektrum. lbarat seperti proses menghasilkan foto dengan melakukan 'freezeframe' atas suatu obyek bergerak, yang dihasilkan adalah representasi kejadian (moment) tapi selalu ada kekurangan yaitu absence-nya 'movement' (realitas) dalam hasil foto tersebut [9: 28]. Identitas beroperasi melalui hadirnya kekurangan ('subsume a lack), yaitu teridentifikasinya sesuatu yang absen hadir, sesuatu yang berbeda ('difference') dari yang ditampilkan [9]. Pada sesuatu yang absen hadir itulah realitas tentang identitas itu hadir. Fenomena absen (kosong) atas realitas ini adalah juga bagian dari identitas, dan dengan mekanisme absen ini-lah, identitas menjadi dinamis, karena justru realitas di balik apa yang terlihat (representasi) itulah esensi dari identitas.

Identitas arsitektur menjadi moda kritis untuk membedah aspek sosial budaya arsitektur, dan bukan hanya untuk pengklasifikasian arsitektur semata. Oleh karena itu identitas selalu bersinggungan dengan dinamika sosial (kelas, ras), budaya (ekonomi, gender, etnis, reliji) dan politik (kuasa, dominasi, resistensi), dan dalam hal ini mempengaruhi subyek identitas itu sendiri. Pertanyaan yang relevan dengan kondisi ini selanjutnya adalah "Whose architectural identity?" dan bukannya "What is architectural identity?" 
Selanjutnya, identitas arsitektur bersifat kontekstual dan situasional ('contingent') [2]. Identitas sendiri dapat berkembang, menyusut atau musnah menyesuaikan dengan konteksnya. Dalam hal ini, konteks dan identitas saling membutuhkan. Ketika konteks kurang memberi asupan (cenderung stabil) bagi berkembangnya identitas, maka identitas juga menjadi stagnan dan lama-kelamaan terjadi fixasi (tidak berubah) yang dapat mengakibatkan berhentinya vibrasi identitas.

Sementara itu politik, secara etimologi berasal dari bahasa Yunani 'polis' ('city'). 'Polis' ini mempunyai agen disebut 'polite' ('a citizen'), dengan adjective-nya adalah 'politikos' ('of a citizen/the citizens, of the state'). 'Politikos' ini dalam bahasa Latin menjadi 'politicus', dalam bahasa Perancis menjadi 'politique', dan dalam bahasa Inggris menjadi 'politic' [17:509]. Politik secara harfiah diartikan sebagai suatu yang mengatur hubungan antara warga (citizen) baik dalam lingkup polis (city) maupun negara (state).

Adapun perbedaan antara 'identitas politik' (political identity) dengan 'politik identitas' (political of identity), menurut Haboddin, adalah bahwa 'political identity merupakan konstruksi yang menentukan posisi kepentingan subjek di dalam ikatan suatu komunitas politik sedangkan political of identity mengacu pada mekanisme politik pengorganisasian identitas (baik identitas politik maupun identitas sosial) sebagai sumber dan sarana politik' [6]. Dengan demikian politik identitas merupakan suatu sikap yang didasarkan pandangan politik tertentu dalam hubungannya dengan aspek kuasa (power), kepemerintahan (governmentality), kewargaan (citizenship) dengan mengambil fokus pada isu-isu identitas seperti gender, race, ethnicity, religion atau sexual orientation untuk suatu tujuan tertentu.

Subyek dalam arsitektur merepresentasikan identitas sekaligus aktor dalam politik identitas, yang merupakan realitas di balik representasirepresentasi visual yang terjadi. Realitas dalam politik identitas ditandai oleh beroperasinya kuasa dan politik ekonomi dalam rangka memperkuat posisi politik elit.

Arti dari representasi diungkapkan oleh Hall (1997) yang mengatakan bahwa 'Representation is the production of the meaning of the concepts in our minds through language.' [7:17]. Oleh karena itu representasi sangat erat kaitannya dengan proses sosial budaya yang memproduksi arti (meaning).
Dengan demikian, menurut Hall pula bahwa Representasi sangat erat hubungannya dengan identitas dan pengetahuan. [7: 5]

\section{Arsitektur Indonesia}

Wacana politik identitas arsitektur di Indonesia sudah hadir sejak lama, khususnya sejak zaman kolonial [8], berlanjut hingga zaman pasca kolonial dan periode pasca reformasi [13 \& 23]. Pada masa pasca kolonial hingga reformasi, paling tidak telah muncul empat generasi arsitek Indonesia, dan dari empat generasi ini lalu muncul paling sedikit tiga arus (faksi) pemikiran arsitektur [21]. Dari tiga arus ini lalu muncul berbagai istilah mengenai 'Arsitektur Indonesia' (catatan: istilah Arsitektur Indonesia sering digunakan oleh Van Romondt), seperti antara lain 'Arsitektur Nusantara', 'Arsitektur Tropis Indonesia' dan 'Arsitektur Tepat Guna' [21]. Namun dalam periode ini, di balik proses pencarian identitas itu sendiri, arsitektur Indonesia menjadi jumud karena ketidakmampuan profesi dan akademisi berdialog dengan disiplin lain. Kritik menarik diutarakan oleh sejarahwan arsitektur Sudrajat (1991) bahwa 'a broadly based history of architecture would have the potential to bridge some extraordinarily interesting interdisciplinary issues... We would anticipate, for example, research which is more sensitive to political matters and social justice' [21:2201].

Pasca reformasi, berbagai seminar dan workshop telah diadakan untuk melihat kemungkinan-kemungkinan arsitektur Indonesia masa depan. Salah satunya diungkapkan oleh Passcher (2007), yang berupaya melihat identitas sebagai suatu kelanjutan sejarah, bahwa sejarah masa lampau menjadi referensi, yaitu

Indonesia today, with the presence of an indigenous and colonial architectural urban heritage has to deal with questions regarding historical-cultural value and the preservation, re-use or demolition of buildings. Beside this historical-cultural importance, what is the significance of the architectural heritage nowadays and is there actually a role for it to fulfil? In the field of architecture, the colonial episode left behind environmental qualities, structures and buildings. Those architects all functioned in and derived their references from the colonial situation. Their clients were commercial bodies or private individuals who were located 
in the upper strata of society. The legacy is perhaps a product of the past, but nevertheless, the colonial architectural products form a substantial part of the daily environment and décor of almost every Indonesian. Architecture, historical or modern, is an exponentional product of society in past or present. [18]

Passcher mengemukakan kesulitannya memprediksi masa depan Indonesia termasuk arsitekturnya di tengah-tengah urbanisasi dan modernisasi yang tidak bisa dibendung dan meningkatnya jumlah populasi khususnya di kota-kota besar. Menurut Beliau (2016), Indonesia is working hard on improving its infrastructure to ensure the quality of life in the future'. [19:238]

Sementara itu Widodo (2007) dalam upayanya mencari identitas kontemporer arsitektur Indonesia di balik menjamurnya 'corporate style architecture' dan juga pembangunan sektor swasta (shopping mall, apartemen, hotel resort) pasca reformasi, sedikit memberi sentuhan mengenai pentingnya 'community approach' dan juga 'architectural experimentation' oleh generasi baru para arsitek [22:23]. Namun sayangnya pendekatan 'identitas' arsitektur yang Widodo lakukan sebelumnya masih sangat morfologis yaitu melalui pendekatan tipologi fisik bangunan. Padahal, dalam aspek sosial-politik, identitas sangat dinamis dan kadang-kadang bermuatan subversif.

Pendekatan yang cukup kritis kemudian diangkat oleh Abidin Kusno (2011), ketika dia melihat fenomena generasi muda dalam perkembangan arsitektur melalui kacamata modernisme dan poskolonialisme. Gerakangerakan baru pasca AMI menjadi bagian dari suatu dinamika sosial dan memberi peluang munculnya suatu strategi sosial bagi suatu intervensi budaya terkait aspek sosio-politik. Kusno menyatakan bahwa,

In the end what is striking about the construct of modernism in Indonesian historiography is a continuous allusion to the theme of youth (muda). This notion however connotes less a kin relationship or a subordinate form of that relationship. Instead, as mentioned earlier, the notion of "muda" refers to pemuda, the term born of the Revolution and the struggle for independence. The term looks to the future as in the language of youth and in some ways rebellion. "Pemuda" exudes newness and radicality. Its meaning derives from the era of revolution. The terms such as "Pemuda" and "Jong" were invented during the struggle for decolonization. The continuous retrieval of these terms seems to suggest that revolutions have not yet been completed. Perhaps it is in this sense that the movements of Indonesian architecture, from one generation to the next, seem to posses a quality of protest that we associate with modernism. To appreciate such production is to see modernism less as a form, but as a vehicle of thought, a social strategy of cultural intervention in relation to the governmentality of the Indonesian state and societal organization which in securing social order give modernism a meaning. [14]

Hal yang diutarakan oleh Kusno, menjadi semacam 'jeda' atau 'rupture', dalam dinamika identitas arsitektur di Indonesia. Namun sejauh mana aspek strategi sosial dalam hubungan dengan 'governmentality' dan 'social order' seperti tersebut di atas menjadi realitas bagi modernisme untuk memberi kontribusi yang berarti? Apakah kemudian ini akan menjadi semacam 'regime' arsitektur baru berikutnya?

\section{Politik versus Identitas}

Masuknya wacana politik identitas dalam arsitektur di Indonesia, selain melalui publikasi-publikasi arsitektur luar negeri juga bersinggungan dengan pemikiran-pemikiran para kritikus dari disiplin di luar ilmu arsitektur seperti kajian-kajian sosial, budaya, poskolonial dan gender/Feminisme (seperti antara lain Henri Lefebvre, Homi K. Bhabha, Edward Said, dan Gayatri Spivak).

Pasca reformasi, kita bisa mengidentifikasikan paling sedikit dua issue yang berlanjut (kontinuitas) terkait arsitektur Indonesia dan politik identitas, yaitu melalui perspektif antropologi (issue indigenitas), hermenetika (issue penafsiran atas kebaharuan), dan semiotika (penanda era)

\section{a. Indigenitas}

Masalah politik identitas yang sangat menonjol sejak zaman Orde Baru dan masih berlanjut hingga pasca reformasi saat ini adalah terkait persoalan penduduk asli (indigenitas). Persoalan klasik adalah seringkali arsitektur melalui berbagai sinkretisasi estetika visual 
dan 'modern miniature theme park', sengaja atau tidak sengaja menjadi media explorasi etnografis atas suku-suku atau etnis tradisional ini melalui obyektifikasi, exotifikasi dan identifikasi atas kehidupan keseharian mereka yang justru merendahkan martabat masyarakat terasing/tradisional tersebut.

Persoalan dilema indigenitas dan krisis ruang bertinggal bisa menjadi sisi yang lain yang terabaikan. Tragedi telah dialami oleh Orang Rimba yang tersebar di beberapa pulau di nusantara dan oleh pemerintah kemudian diberi nama Suku Anak Dalam, nama yang menurut pemerintah dianggap lebih 'beradab'.

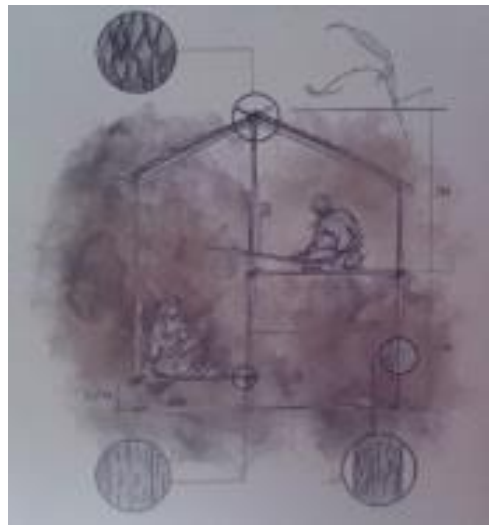

Rumah de Tanoh, sketsa Tim Ekskursi UI

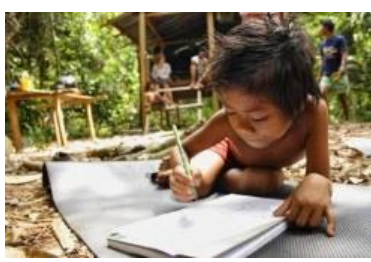

Sokola Rimba

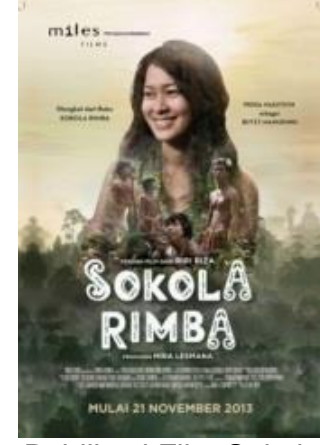

Publikasi Film Sokola Rimba

Gambar 2. Orang Rimba dan ilustrasi kehidupan mereka di Taman Nasional Bukit Dua Belas Jambi. (Sumber: Tim Ekskursi Taman Nasional Bukit Dua Belas Jambi 2014 Departemen Arsitektur FTUI, dan Film 'Sokola Rimba' (2013) yang disutradarai Riri Riza)

Contoh lain, dalam rangka keperluan administrasi pencatatan sipil, pemerintah setempat mendata status Orang Rimba yang menghuni Taman Nasional Dua Belas Jambi. Mereka bukan beragama Islam, namun supaya mudah pemerintah mencatatkan mereka sebagai pemeluk agama Islam dengan tanggal lahir yang seragam, angka tahun yang berbeda-beda. Tidak hanya itu saja, dalam rangka mengubah pola hidup berpindah menjadi menetap, pemerintah, melalui proyek perumahan suku terasing, juga membuatkan puluhan rumah sederhana (yang lebih tepat disebut sebagai bedeng shelter) secara cumacuma di tepi-tepi jalan besar yang dindingnya terbuat dari GRC beratap seng, sangat kontras dengan bangunan asli Orang Rimba yang sebenarnya. Politik 're-settlement' ini, sedikit demi sedikit membuka isolasi dan mengeluarkan Orang Rimba dari Rimba. Namun sangat menyedihkan, di balik itu ternyata kegiatan deforestasi ilegal justru semakin meluas dan semakin mengancam ruang habitat Orang Rimba yang sebelumnya telah tersingkir akibat pembukaan lahan perkebunan dan permukiman transmigrasi. Fenomena Orang Rimba menarik produser Mira Lesmana untuk mengabadikannya melalui layar kaca dengan mengangkat tema Sokola Rimba [12]. Film tersebut memberi sentuhan kemanusiaan dan sosial yang kuat yang diwarnai intervensi politik identitas (Gambar 2).

\section{b. Penafsiran atas kebaharuan}

Kebaharuan menjadi penanda perubahan atas masa lampau yang dianggap ketinggalan zaman, tidak modern (kuno), terbelakang dan suram. Oleh karena itu segala sesuatu yang dianggap 'old fashioned' mesti diperbaharui agar tampil lebih modern dan segar. Peremajaan kembali menjadi salah satu metode dalam memenuhi tuntutan kebaharuan ini. Pasca Orde Baru berlanjut tindakan yang pragmatis dalam menafsirkan tentang identitas modern dan kebaharuan ini. Pengaplikasian kebaharuan dalam wajah arsitektur modern yang lama dilakukan melalui artikulasi peremajaan.

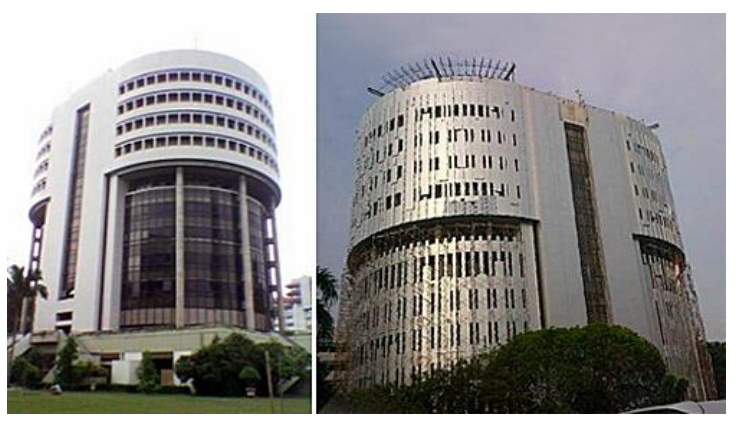

Gambar 3. Facade Gedung LIPI yang diberi 'Sarung'. (Sumber:

http://esubijono.wordpress.com/2013/03/06/peremai aan-bangunan-di-jakarta/)

Upaya peremajaan bangunan modern yang ketinggalan zaman dilakukan melalui 'face off atau 'penyarungan' [25]. Tengoklah facade baru Gedung LIPI Jakarta (aslinya dirancang 
oleh Arsitek Ir. N. Siddharta dari AT-6), yang sekarang ditutupi dengan panel-panel komposit metal (Gambar 3). Penyarungan dengan maksud peremajaan memberikan arti selain untuk menutupi realitas wajah sesungguhnya (lama), merupakan upaya praktis agar nanti mudah diganti kembali.

\section{c. 'Penanda' era}

Berbagai simbol fisik arsitektur berupa monumen, memorial, ruang publik dan bangunan merepresentasikan aspek sosial politik pada suatu masa khususnya terkait kekuasaan yang sedang berlangsung pada saat itu. Regime Orde Lama dan Baru samasama menggunakan arsitektur sebagai media untuk menandai era masing-masing. Jika di era Orde Lama, Soekarno menggunakan bahasa antar bangsa (internasional) sebagai landasan bagi monumen dan bangunan yang digagasnya, sebaliknya era Suharto menguatkan bahasa ke-Indonesia-an (indigenisasi) melalui artikulasi arsitektur tradisional sebagai langgam penanda era tersebut. Selain itu, sejak dari masa Soekarno dan Soeharto, pembangunan yang berorientasi vertikal mulai menjadi sesuatu yang 'mesti'. Aneka monumen dan bangunan pencakar langit awal yang dibangun pada masa Soekarno untuk kota Jakarta, yang dilanjutkan pada masa Suharto, menjadi struktur yang mesti hadir sebagai penanda Jakarta layak bersaing dengan berbagai ibukota negara lainnya di dunia baik yang sudah lebih maju maupun yang dianggap masih setara dengan Indonesia (Malaysia dan Thailand).

Pada masa Orde Baru, pemerintah pernah menggagas rencana pembangunan 'Menara Jakarta', sebagai bangunan tertinggi di Indonesia dan Asia yang berlokasi di eks bandara Kemayoran, melalui sebuah sayembara terbatas (1995/1996). Namun rencana besar ini tidak pernah terwujud karena setahun sesudah berlangsungnya sayembara tersebut, rezim Orde Baru tumbang. Selain Menara Jakarta, ada beberapa bangunan menara lain yang juga belum jadi dibangun karena Indonesia memasuki era krisis ekonomi pada pertengahan dekade 1990-an. Ide untuk memberi tanda dalam ruang kota melalui bentuk karya arsitektural disponsori oleh para taipan, konglomerasi dan perusahaan milik negara yang kuat secara finansial.

Ide ini kemudian muncul kembali pasca tahun 2010, seiring membaiknya perekonomian Indonesia yaitu melalui rencana pembangunan Gedung Signature Tower (milik pengusaha
Tomy Winata dan dirancang oleh Arsitek asing dari Smallwood, Reynolds, Stewart, Stewart and Associates Inc. (SRSSA) yang dibantu PDW Architects sebagai mitra lokal) di kawasan SCBD Jakarta setinggi 638 m (111 lantai) dan Pertamina Energy Tower (milik BUMN Pertamina dan dirancang oleh Skidmore Owings Merrill (konsultan utama) yang bermitra dengan PT Airmas Asri dan PT Wiratman sebagai konsultan lokal) setinggi 523 m (99 lantai) di kawasan Rasuna Episentrum Kuningan Jakarta. [12]

\section{Ekses sebagai Tantangan}

Selain tiga issue keberlanjutan politik identitas model lama seperti dijelaskan pada sub bab sebelumnya, pada pasca reformasi kita melihat suatu fenomena arsitektur baru sebagai ekses dari dinamika politik identitas dan modernitas yang terjadi melalui menguatnya lokalitas dan tantangan revitalisasi serta kekuatan global baru.

\section{a. Menguatnya lokalitas}

Fenomena yang terjadi pasca reformasi adalah menguatnya politik identitas di ranah lokal seiring menguatnya politik desentralisasi. Pasca pemberlakuan UU No. 22/1999 (tentang otonomi daerah), gerakan politik identitas semakin jelas wujudnya. Menurut Haboddin, 'banyak aktor politik lokal maupun nasional secara sadar menggunakan isu ini dalam power-sharing.' [6]

Tahun 2013, Gubernur DKI Jakarta (joko Widodo) menggulirkan wacana untuk menghadirkan ciri 'Betawi' dalam berbagai kegiatan dan material budaya di Jakarta. Dalam bidang Arsitektur, gedung-gedung publik dianjurkan untuk berarsitektur khas Betawi. Pertanyaan yang justru muncul adalah apakah Jakarta itu identik dengan Betawi? dan apakah Betawi itu identik dengan Jakarta? [23], lalu entitas Betawi mana yang mewakili Jakarta? Gugatan ini justru mempertegas menguatnya politik identitas di balik validitas 'identitas' itu sendiri.

Contoh tentang Jakarta menjadi menarik jika kita sandingkan dengan provokasi Cornelis Lay (2003) yang menulis: 'Jakarta Berkata, Akulah Indonesia'.[15] Fenomena menguatnya wewenang pemerintah/politik kedaerahan pasca reformasi menggugat eksistensi dominasi Jakarta, memunculkan pertanyaan baru tentang apa yang dilontarkan oleh Gubernur DKI terkait dengan identifikasi budaya Jakarta dan Non-Jakarta. Dalam struktur organisasi profesi arsitektur di Indonesia sendiri, menguatnya peran cabang- 
cabang di daerah juga menarik untuk disimak. Justifikasi yang sering digunakan adalah melalui perumpamaan lingustik yaitu melalui bahasa nasional yang mengambil bahasa Melayu sebagai bahan dasar dan bukan bahasa Jawa atau Betawi. Hal ini karena bahasa Melayu lebih banyak tersebar dan menjadi bahasa penghubung perdagangan lekonomi yang lebih dikenal di nusantara dibandingkan bahasa Jawa atau bahasa Betawi.

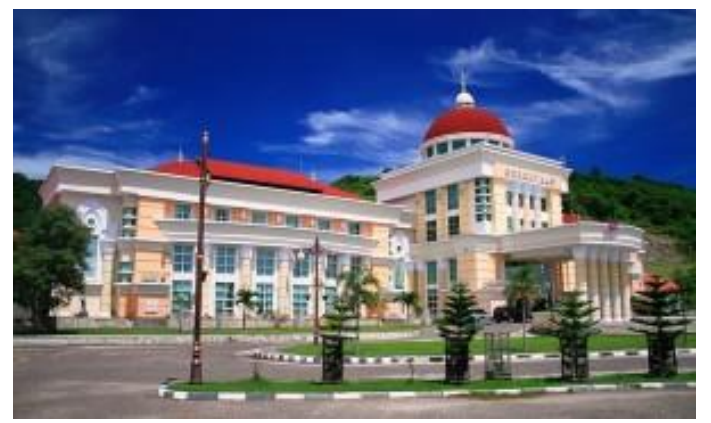

Gambar 4. Kantor Gubernur Pemerintah Propinsi Gorontalo yang terletak di atas Bukit terinspirasi dari Capitol Hill di Washington DC. Curamnya jalan menyulitkan kendaraan roda dua untuk mencapai bangunan tersebut. (Sumber:

http://pesonawisataindonesia.com/pesona-wisatagorontalo-kantor-gorontalo/)

Menguatnya sentimen kedaerahan ini adalah akibat dibukanya keran desentralisasi setelah sebelumnya sentralisasi begitu kuat dipraktekkan. Politik lokal memberikan pengaruh dalam arsitektur yaitu berupa praktek apartheid terhadap arsitektur non-lokal (mana yang asli dan mana yang bukan). Selain itu, politik lokal memberikan kesempatan bagi elit politik di daerah untuk membangun monumen ('jejak kekuasaan') dan identitas arsitektur daerah menurut interpretasinya sendiri. Hal yang menarik adalah beberapa daerah menjadikan arsitektur asing sebagai referensi utamanya. Perubahan ini menggambarkan adanya peralihan dari 'mindset' poskolonialisme (nasionalisme) menjadi mindset 'pos-nasionalisme' yaitu berupa 'etno-nasionalisme.'[12]

Perayaan simbol-simbol kedaerahan menjadi identitas baru bagi daerah yang terjadi melalui paling sedikit dua cara: a) hadir sebagai identitas baru kedaerahan atau jelmaan neoregionalisme (seperti Komplek baru perkantoran Gubernur dan DPRD Gorontalo yang meniru Capitol Hill di Washington DC (Gambar 4), atau penggunaan atap kubah pada berbagai bangunan publik di Aceh pasca peristiwa Tsunami dan penerapan syariat Islam, rencana pembangunan airport-airport baru yang megah di daerah-daerah terpencil), lalu b) hadir sebagai identitas baru tapi dengan menghancurkan identitas yang sudah ada sebelumnya (dapat dilihat melalui masjid $A R H$ UI baru (di Salemba Jakarta) yang didukung oleh dana dari pemerintah Saudi Arabia dan dibangun bergaya Oriental Timur Tengah dengan menghancurkan masjid $\mathrm{ARH}$ modernist tahun 1970-an beratap datar), atau c) hadir dengan menumpang arsitektur yang sudah ada (permukiman 'Betawi' Setu Babakan yang merupakan simulasi budaya Betawi oleh Pemda DKI, dan juga gerbang Passer Baroe Jakarta yang bergaya arsitektur Tionghoa).

\section{b. Tumbuhnya Pusat-Pusat Baru}

Pasca reformasi tahun 1997, kota-kota di luar pulau Jawa bertransformasi dan menjelma menjadi metropolis-metropolis baru (antara lain: Palembang, Medan dan Makassar). Kotakota tersebut menjadi alternatif pusat ekonomi baru selain Jakarta. Desentralisasi pascakolonial telah memungkinkan bergesernya dan terdistribusinya peran 'pusat' ke wilayah di luar pulau Jawa. Pusat-pusat ekonomi baru di luar Jawa tumbuh sejalan dengan meningkatnya peran daerah dalam panggung sosial-politik kenegaraan.

Modernitas poskolonial melahirkan ekses yaitu munculnya fenomena 'hyper complexity' yang menyebar ke hampir seluruh kota seiring dengan menguatnya politik kedaerahan. 'Multiplicity' dalam fenomena pragmatisme urban menjelma menjadi 'hyper-complexity'. Urban kampung pasca kolonial bertranformasi menjadi sebuah permanen 'hyper-informality' yang berisikan bangunan bergaya betonmetal-alumunium dan tidak terencana. 'Multiplicity' membentuk skyline kota di Indonesia dan merepresentaskan pertumbuhan yang terjadi di area kampung kota. Fenomena 'mutiplicity' (hyper-complexity) membuka pertanyaan akan nasib perencanaan kota di Indonesia ke depannya. Leonie Sandercock mengkritisi perencanaan kota modern yang menutupi peran kelompok marginal termasuk kelas pekerja, kelompok minoritas, kelompok difabel, dan wanita [20]. Sandercock, didasarkan pada masyarakat yang semakin terbuka dan demokratis saat ini, memperingatkan para perencana kota agar lebih mengenal perbedaan budaya masyarakat yang semakin kompleks dan mobilitas masyarakat kota di tengah arus cepat pertumbuhan kota itu sendiri dalam rangka menghindari terjadinya ekses urbanisasi yang ditimbulkan akibat eksklusi sosial, represi dan marginalisasi. [20] 
Sementara itu, pertumbuhan ekonomi wilayah juga memicu pertumbuhan kota-kota kecil yang masih mempunyai nilai-nilai tradisional yang khas namun berpacu dalam beradaptasi dengan modernitas yang sulit dibendung. Kota-kota kecil yang dulunya mengandalkan kekayaan alam seperti hasil pertanian, perkebunan, perikanan dan pertambangan mesti mencari strategi baru agar bisa bertahan dengan menipisnya unsur hara, perubahan cuaca dan lingkungan alam, serta menipisnya persediaan bahan tambang. Sebagai contoh adalah kota Sawah Lunto (Sumatera Barat) dan Muntok (Kepulauan Bangka-Belitung) yang mengandalkan industri pertambangan di masa lampau. Fenomena yang terjadi di beberapa kota yang memudar identitasnya akibat meredupnya aktivitas ekonomi sangat menarik untuk diamati. Sawah Lunto di Sumatra Barat mengalami perubahan identitas, dari kota tambang menjadi kota 'wisata' tambang zaman kolonial (2005) akibat berhentinya produksi Batubara di kota tersebut. Walaupun awal peralihan ini secara sosial politik dilakukan melalui pendekatan topdown namun kemudian didukung secara bottom - up. Peran sejarahwan seperti Erwiza Erman [3] yang mengangkat sejarah 'orang rantai' zaman kolonial untuk mengisi cerita baru Sawah Lunto (2007), memunculkan potret identitas masa silam yang kelam sebagai komoditas yang mendukung kegiatan pariwisata. Perubahan ini (preservasi dan revitalisasi) menitikberatkan rekonsiliasi di semua lapisan masyarakat dengan mengandalkan aset 'heritage' kota melalui pendekatan 'adaptive-reuse'.

\section{c. Globalisasi oleh kekuatan asing baru}

Globalisasi telah menghadirkan dunia yang seolah menjadi satu tanpa sekat, dan cenderung seragam, dimana fenomena budaya baru di sebuah negara juga bisa terjadi dan cepat menyebar ke berbagai belahan dunia lainnya akibat teknologi informasi dan sosial media yang tidak bisa terbendung lagi. Begitu juga dalam ranah arsitektur.

Era pasca reformasi telah menyediakan kesempatan lebih banyak bagi interaksi silangbudaya antar bangsa (multikulturalisme) akibat globalisasi dan juga peran sosial media. Hal ini dibuktikan dari makin banyaknya kolaborasi antar kebudayaan yang diinisiasi oleh berbagai komunitas mulai dari masyarakat biasa, artis, arsitek, akademisi, perwakilan Lembaga Swadaya Masyarakat dan budayawan.
Politik identitas pasca Orde Baru semakin menarik ketika kita melihat semakin agresif dan derasnya budaya asing tertentu masuk ke Indonesia. Sebagai contoh adalah populernya budaya pop dari Korea (seperti gangnam style), meningkatnya popularitas peralatan elektronik aneka gadget bermerk asal Korea, dan menjamurnya film-film dan musik Korea, yang berlanjut dengan kedatangan artis-artis Korea dalam industri hiburan di Indonesia. Kini, bahkan dalam bidang arsitektur, KAAB, Lembaga Akreditasi Arsitektur Korea juga berhasil menempatkan dirinya untuk memberikan akreditasi bagi Sekolah-sekolah Arsitektur di Indonesia. Korea telah menjelma menjadi kekuatan asing baru dalam aspek ekonomi bahkan dalam hal pendidikan dan profesi arsitektur

\section{Identitas Arsitektur}

In the Indonesian architectural
discourse, the notion of identity is
understood merely as something
related to fixed, static and final
outcomes. This is affected by the
condition in Indonesian architectural
education and also the cultural
mindset amongst Indonesian scholars
who have treated architecture and
urbanism as mainly collections of
monolithic solitary buildings. In order
to escape from this traditional regime
of thinking, this notion must be
rethought and brought to the
comprehension that identity is a
theoretical device rather than merely a
traditional agent for building's
classification and identification. [11:13]

Identitas arsitektur bersifat rentan terhadap intervensi dan bisa mengandung muatan subversif, baik personal, sosial maupun geopolitikal. Sebagai contoh penghancuran bangunan-bangunan kolonial akibat sentimen anti-kolonial pada masa Orde Baru, juga pembakaran dan penjarahan berbagai sarana komersial dan permukiman kelompok etnis dan agama tertentu yang mewarnai konflik etnis dan agama di beberapa daerah di Indonesia (Poso, Ambon, Pontianak) pasca reformasi 1998. Hal ini bersamaan pula dengan aksi terorisme yang menghantam bangunan klub-klub untuk orang asing di Bali yang juga berlanjut pada beberapa gedung penting di Jakarta yang merepresentasikan kekuatan kapitalisme asing.

Hall menyampaikan pentingnya subyektifitas dalam menemukan identitas, yaitu 'one of the places that we have to go to is certainly in the 
contemporary languages which have rediscovered but repositioned the notion of the subject, of subjectivity' [10:45]. Dalam pemahaman identitas seperti ini, Hall mengusulkan sebuah konsep baru identitas yang ia sebut 'a new hybrid postcolonial subject'. Jika melihat yang terjadi di Indonesia, istilah ini lebih tepatnya menjadi 'a new hybrid ethno-national subject.'

Masyarakat Indonesia yang menghormati bahasa simbol menempatkan figuritas individu sebagai hal yang sangat penting. Dalam hal ini pemimpin-pemimpin, baik yang formal maupun informal, dalam masyarakat mempunyai pengaruh yang kuat. Identitas yang dikatakan Hall bersifat hybrid mempunyai sifat 'consociational' yaitu melalui konsensus keterwakilan pemimpin-pemimpin dalam masyarakat. Kepemimpinan yang kuat dan adil sangat dibutuhkan agar masyarakat yang memiliki hubungan dan kepentingan dengan representasi-representasi identitas tadi, namun berada di luar proses politik identitas tersebut, tidak mengalami 'displacement' (suatu perasaan 'being out of place), ataupun 'dislocation' (berhubungan dengan 'alienation'), dan juga fragmentation (guncangan 'multiple identities')' [9:224]. Oleh karena itu, bila melihat sejarah arsitektur di Indonesia, simbol-simbol sosial dalam masyarakat ini memegang kunci sebagai representasi masyarakat sekaligus figur penting yang menyatukan dalam mengkonstruksi dan memproduksi ruang arsitektur dan kota. Dengan kata lain identitas ruang kota ditentukan melalui subyek yang mendominasi melalui relasi kuasa tertentu.

Lebih lanjut, dalam rangka menjawab impak negatif globalisasi pada masyarakat yang sedang mengalami transisi, dari masyarakat tradisional yang tertutup ke masyarakat yang demokratis dan terbuka, maka pendekatan perspektif multikulturalisme menjadi penting dalam mendefinisikan ulang identitas arsitektur Indonesia ke depan. Hal ini dikarenakan pendekatan multikutural dapat menghindari bias dan ketidak adilan terhadap kelompok marginal dan masyarakat yang berada di luar proses politik identitas [11:20]. Perspektif multikultural membuka ruang negosiasi bagi kemunculan ruang ketiga (hybrid).

Pada bagian ini, saya mencoba meneropong dua fenomena di Indonesia untuk melihat kemungkinan produksi identitas ruang baru yaitu melalui Kearifan Lokal dan Nilai Pusaka (Heritage) sebagai Masa Depan dan Keberlanjutan Lingkungan dan Realitas Sosial sebagai Rujukan Utama dalam ber-ArsitekturKota.

\section{a. Kembali ke Kearifan Lokal dan nilai} Pusaka (Heritage) sebagai 'Masa Depan' Inspirasi menarik pola-pola strategi sosial kontemporer terhadap intervensi ruang budaya dapat kita saksikan salah satunya melalui kegiatan Rumah Asuh yang digerakkan oleh Yori Antar dan kawan-kawan beserta Yayasan Tirto Utomo. Beberapa proyek yang sudah berjalan seperti Sumba, Mbaru Niang di Waerebo (2013), Nias dan Sumpu, melibatkan peran figur-figur kunci yang mampu menggerakkan masyarakat. Di balik istilah 'Asuh' terdapat realitas mengenai tuntutan akan 'safe-guarding', 'resistance/resilience' dan juga komodifikasi kebudayaan. Hybrid yang terjadi melalui kolaborasi 'outsider' yaitu arsitek profesional dan 'insider' yaitu masyarakat setempat yang pada dasarnya merupakan tindakan penyelamatan nilai kearifan lokal dan nilai warisan budaya (heritage). Kolaborasi dan komodifikasi sistem sosial membangun yang dilakukan bukan hanya merekontruksi identitas tapi juga mereproduksi ruang melalui pola intervensi baru, yaitu adanya dukungan dana dari philantropi.

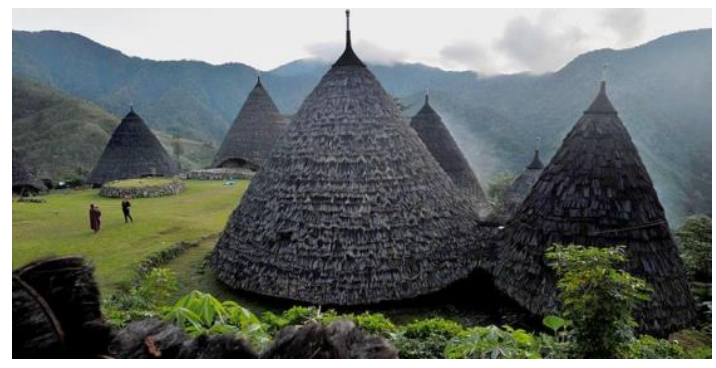

Gambar 5. Arsitektur tradisionaldi Waerebo. (Sumber: Kompas.com, 2016)

Tantangan baru yang muncul di balik citra harmoni dan suasana damai yang dihadirkan dalam rekonstruksi rumah adat di pedalaman Waerebo adalah realitas arus modernisasi (dihadirkan oleh para turis) dan dilema ruralisasi. Bahasa realitas yang diungkapkan, subyek keseharian di Waerebo menjadi tantangan bagi orang luar untuk benar-benar tahu apa yang sesungguhnya terjadi di Waerebo. Pembangunan Mbaru Niang menyimpan 'hidden social reality.' [27]. Mbaru Niang menjadi proyek yang memicu perbaikan-perbaikan lingkungan yang terjadi di Waerebo. Pasca pembangunan Mbaru Niang, produksi identitas arsitektur akan terus terjadi di hari-hari selanjutnya, dan kemungkinan tantangan yang dialami Waerebo ke depannya semakin meluas, seiring terbukanya isolasi 
wilayah dengan pembukaan jalan akses seperti yang diminta oleh penduduk setempat. Akankah Waerebo menjadi 'Apocalypto' masa kini dengan masuknya pendatang-pendatang baru nantinya?

Waerebo hanyalah satu contoh kecil di Indonesia. Selain Waerebo, penggiat arsitektur di Indonesia juga berkiprah dalam kegiatan pelestarian pasca reformasi melalui lembagalembaga kemasyarakatan (Non-Government Organization - NGO) seperti Badan Pelestarian Pusaka Indonesia (BPPI), Jaringan Kota Pusaka Indonesia (JKPI), Pusat Dokumentasi Arsitektur (PDA). Muncul istilah 'Pusaka' sebagai terjemahan dari 'Heritage' untuk memberikan penekanan pada aspek non-ragawi melalui pelestarian nilai-nilai pusaka bagi kelangsungan identitas bangsa.

Keberadaan Undang-Undang Cagar Budaya no: 11 tahun 2010 (menggantikan UU Cagar Budaya tahun 1992 yang sudah tidak sesuai dengan perkembangan) memberikan arah dan fondasi legal bagi kegiatan pelestarian selanjutnya. Muncul berbagai program pelestarian pusaka oleh beberapa kementerian terkait, salah satunya adalah Program Pelestarian dan Pengembangan Kota Pusaka (P3kP) di bawah kementerian Pekerjaan Umum sejak tahun 2013.

'Heritage' menjadi semacam trend gaya hidup 'modern' bagi masyarakat kelas menengah di perkotaan, menunjukkan masyarakat semakin eksploratif menjelajah ruang-ruang identitas baru bagi masa depan mereka.

Lebih jauh lagi, penggiat arsitektur tanah air semakin melihat 'Indonesia' sebagai sumber inspirasi kreatifnya pasca dicanangkannya 10 destinasi Wisata Prioritas Indonesia tahun 2016 dan direvitalisasinya berbagai bandara perintis di berbagai daerah terpencil yang semakin memudahkan kunjungan ke berbagai daerah berarsitektur menarik di Indonesia. Hal ini memberikan alternatif baru bagi publik untuk mengeksplorasi Indonesia lebih jauh. Beberapa sayembara arsitektur yang mengangkat pesona arsitektur tradisional di Indonesia telah menarik minat para arsitek muda dan mahasiswa, seperti sayembara perancangan Rumah Wisata (Homestay) Nusantara tahun 2016 dan restoran Nusantara tahun 2017 (diselenggarakan oleh IAI dan Propan). Selain itu, Badan Ekonomi Kreatif (BEKRAF) Indonesia menjadikan arsitektur sebagai salah satu target pengembangan industri kreatif yang potensial memberikan nilai tambah bagi negara. Salah satunya dicerminkan melalui kegiatan Pameran
'Tanahku Indonesia' 2017 yang berangkat dari tema 'materialscape' dengan mengkompilasi berbagai material 'tanah' yang berhubungan dengan berbagai tradisi membangun di Indonesia sebagai bahan dasar untuk bisa diolah lebih jauh sebagai industri kreatif Indonesia masa depan.

\section{b. Keberlanjutan Lingkungan dan Realitas Sosial sebagai Rujukan Utama dalam ber-Arsitektur-Kota}

Realitas praktek arsitektur di Indonesia pasca reformasi dihadapkan pada isu lingkungan dan sosial budaya. Bencana alam yang sering terjadi dan melanda sebagian wilayah Indonesia, jenuhnya arsitektur Indonesia terhadap model-model arsitektur pascamodern dan juga tuntutan dan tekanan ekonomi yang semakin meningkat menjadi pemicu bagi pencarian ranah-ranah arsitektur baru yang belum penah dijangkau oleh para arsitek profesional sebelumnya. Tsunami tahun 2004 yang menerjang Banda Aceh dan sekitarnya telah membuka mata masyarakat 'arsitektur' di Indonesia bahwa ruang kehidupan masyarakat Indonesia sangat dekat dengan isu kebencanaan (letak kepulauan Indonesia yang berada dalam cincin api ('ring of fire') dunia). Perlu adanya perhatian dan pendekatan baru mengenai arsitektur di Indonesia untuk mengantisipasi perubahan-perubahan ruang sekaligus daya tahan masyarakat untuk bisa hidup di wilayah yang rawan bencana alam semacam ini. Isu lingkungan menjadi sebuah paradigma yang menjadi alternatif penting dalam pencarian jati diri, melampaui isu kebangsaan di era Orde Lama dan Orde Baru. Istilah-istilah asing seperti 'urban farming', 'water harvesting', 'biophilic' mulai populer di telinga para penggiat arsitektur di tanah air.

Selain itu, krisis ekonomi dan masalah kemiskinan yang terjadi di masyarakat juga telah mengasah sensitifitas dan memberi peluang baru dalam praktek berarsitektur yang peka terhadap isu sosial khususnya bagi para arsitek generasi muda yang masih lekat dengan idealismenya. Muncul istilah arsitek sosial, yaitu arsitek yang berpihak pada isu sosial dan informalitas. Aspek keseharian (everyday) menjadi penting dalam rangka mengungkap dan mengangkat ruang-ruang terpinggirkan dan terabaikan.

Perubahan aspek geopolitik terhadap ruang bertinggal dan ruang hidup semacam ini ternyata menimbukan ekses, akibat munculnya ruang-ruang baru yang tadinya tidak ada. Ruang-ruang baru ini menjadi arena pertarungan sosial yang berdampak pada kualitas dan keberlanjutan ruang-ruang 
berkehidupan di kota. Gentrifikasi telah melahirkan resistensi terhadap ruang-ruang marginal (contoh: permukiman 'urban kampung') yang masyarakatnya kurang mendapat akses atas ruang-ruang publik dan infrastruktur yang layak. Selain itu, ruang lain ('other') yang tadinya tersembunyi dan tabu untuk diungkapkan karena berhubungan dengan isu gender, rasial, sexual merupakan potensi bagi hadirnya identitas ruang baru.

Persoalan lingkungan dan realitas sosial di Indonesia, menjadi akar identitas tersembunyi bagi ruang-ruang arsitektur dan kota di Indonesia yang mengalami urbanisasi dan transisi dari kota tradisional menjadi kota modern (pasca-tradisional) dengan menguatnya ekonomi [pragmatis]-nya. Identitas tersembunyi ini melekat di balik identitas visual yang tampak di permukaannya, dan formasinya tergantung dari perubahanperubahan pada masyarakat, kondisi geopolitik dan ekonomi selanjutnya.

\section{c. Generasi millenial Arsitek Indonesia}

Gunawan Tjahjono (2016), mengungkapkan ada lima jenis Arsitek di Indonesia, yaitu: 1) Arsitek yang berbakat dan lugu, 2) Arsitek kurang berbakat dan lugu, 3) Arsitek Pelayan, 4) Arsitek kontekstual, 5) Arsitek perancang sekaligus pegiat atau katalis. Dari kelima tipe arsitek ini Gunawan Tjahjono secara khusus menggambarkan arsitek tipe pertama sebagai representasi arsitek generasi 1990-an dan 2000-an yang kurang peka terhadap isu lingkungan (konteks).

'Menurut Gunawan, yang termasuk dalam jenis arsitek ini adalah mereka yang mahir merancang dan mampu mengembangkan kaidah arsitektural. Namun, arsitek ini tidak peka atau kurang peduli terhadap lingkungan atau konteks tempat karya mereka yang akan dibangun. Mereka mengabaikan -sengaja atau tidak, faktor-faktor yang berdampak negatif bagi keberlanjutan lingkungan.' [29],

'Gunawan menengarai arsitek ini cukup banyak di Indonesia terutama yang berkarya pada rentang 1990-an, 2000-an, dan meraih ketenaran pada 2010-an. Dicontohkannya, ada satu karya pemenang Anugerah Ikatan Arsitek Indonesia 1999 yang cukup menyengsarakan penggunanya. Berdasarkan informasi yang diperolehnya, pengguna bangunan mengeluh karena tiap hujan air merembes dan siang hari masih terasa panas walau ada penyejuk ruangan. "Sejauh negara ini belum ada Undang-undang Arsitek maka tak ada hukuman bagi mereka yang mengabaikan tugasnya." [29]

Arsitek tipe pertama (Berbakat dan Lugu) adalah produk perubahan paradigma Pendidikan Arsitektur tahun 1994, yaitu dari pendidikan arsitektur berorientasi profesional (dengan gelar Insinyur, pendidikan selama 5 tahun), menjadi pendidikan arsitektur berorientasi akademik (bergelar Sarjana, pendidikan selama 4 tahun).

Sebagian Arsitek tipe pertama ini sempat merasakan kemunculan Arsitek Muda Indonesia (AMI) dan menjadikan AMI sebagai idola mereka. Ketika anggota AMI generasi pertama menganggap diri mereka 'Tidak Muda' lagi yang menurut Sonny Sutanto diistilahkan sebagai AMI 'Asam Urat', arsitekarsitek generasi selanjutnya memunculkan generasi Pasca AMI yang bergabung dalam kelompok-kelompok seperti Jong Arsitek, Architect Under Big Tree, dan Komunitas Belajar Design.

Refleksi Abidin Kusno mengenai peluang munculnya dinamika baru dalam berarsitektur oleh para arsitek muda sebagai suatu strategi sosial dalam intervensi budaya perlu dicermati. Budaya berarsitektur seperti apa yang nantinya akan muncul dari generasi milenial arsitek Indonesia yang bercirikan mahir menggunakan gadget dan memanfaatkan media sosial sebagai media komunikasi? Suatu hal yang perlu dipersiapkan baik kalangan profesi maupun pendidik arsitektur di Indonesia yaitu munculnya strategi sosial baru dalam praktek arsitektur di Indonesia, khususnya pasca penerapan Undang-Undang no. 7 tahun 2017 tentang Arsitek. Apakah generasi milenial ini masih menganggap bahwa arsitektur adalah 'wujud hasil penerapan ilmu pengetahuan, teknologi, dan seni secara utuh dalam mengubah ruang dan lingkungan binaan sebagai bagian dari kebudayaan dan peradaban manusia yang memenuhi kaidah fungsi, kaidah konstruksi, dan kaidah estetika serta mencakup faktor keselamatan, keamanan, kesehatan, kenyamanan, dan kemudahan' [1]. Ataukah arsitektur menjadi sesuatu yang lebih abstrak tak berwujud ke depannya? Waktu yang akan menjawabnya. 


\section{KESIMPULAN}

Makalah ini mengungkapkan kesulitan dalam merumuskan identitas arsitektur Indonesia yang sering diidentifikasikan secara visual semata. Sementara itu peran politik identitas sebagai salah satu agen penting dalam membentuk formasi identitas Arsitektur itu sendiri sering diabaikan. Identitas arsitektur hadir sesuai konteksnya, namun selalu dalam bentuk yang tidak lengkap, melalui absennya realitas.

Hal yang menjadi perdebatan selama ini adalah pada tataran representasi identitas arsitektur (dan kecenderungan menjauh dari politik identitas). Padahal masyarakat Indonesia sangat familiar dengan bahasa simbol dan menghormati figuritas, sehingga sangat mudah untuk dipengaruhi oleh kuasa melalui pencitraan dan representasi. Oleh karena itu pertanyaan tentang 'Apa identitasnya?' tidak terlalu penting untuk diperdebatkan, tapi tujuan dan latarbelakang kemunculannya yang perlu diperhatikan agar dapat bermanfaat bagi masyarakat yang terwakili dan tidak mengorbankan kelompok identitas lain. Ke depannya, pendekatan multikultural (Bhineka) yang bisa menyatukan (Tunggal lka) perlu menjadi pertimbangan. Identitas bersifat tertentu dan bukan general.

Pasca reformasi kita menyaksikan adanya reindigenisasi di bawah bayang-bayang kontinuitas praktek politik identitas pasca Orde Baru. Seiring menguatnya politik lokalitas, wilayah-wilayah di nusantara khususnya daerah yang mempunyai ekonomi kuat karena mempunyai sumber daya alam yang strategis mempunyai kesempatan lebih dalam menata kembali arsitektur dan kota, termasuk juga upaya adaptasi dan revitalisasi aset heritage yang mesti berhadapan dengan penguasaan ekonomi. Politik identitas akan terus berlangsung dan mendinamisasi proses berarsitektur itu sendiri.

Oleh karena itu, menjadi tanggungjawab warga kota dan warga negara untuk menghadirkan proses berarsitektur dan berkota yang tidak hanya mengandalkan rasio, tapi juga menghadirkan 'rasa' dan 'kesadaran' sosial politik. Membangun identitas arsitektur yang berpihak pada kepentingan kemanusiaan, lingkungan, sosial dan kebudayaan adalah juga bagian dari membangun peradaban di Indonesia.

\section{DAFTAR PUSTAKA}

[1]. .......... Undang-Undang nomor 7 tahun 2017 tentang Arsitek.

[2]. Rendell, Jane, 'Tendencies and Trajectories: Feminist Approaches in Architecture', dalam Crysler, C.G., Cairns, Stephen \& Heynen, Hilde (eds). (2012). The SAGE Handbook of Architectural Theory. Los Angeles: SAGE, hal: 93.

[3]. Erman, Erwiza. (2007). Orang Rantai. Jakarta: Penerbit Ombak bekerjasama dengan Pemerintah Kota Sawah Lunto.

[4]. Gay, Paul Du; Evans, Jessica and Redman, Peter (eds.). (2000). Identity: $\boldsymbol{A}$ Reader. London, Thousand Oaks, New Delhi: Sage Publications. Hal : 28

[5]. Gouda, Frances. (1995). Dutch Culture Overseas: Colonial Practice in The Netherlands Indies 1900-1942. Netherlands: Amsterdam University Press.

[6]. Haboddin, Muhtar. (2012). 'Menguatnya Politik Identitas di Ranah Lokal'. Jurnal Studi Pemerintahan 3: 1: $109-126$.

[7]. Hall, Stuart (ed.). (1997). Representation: Cultural Representation and Signifying Practices. London, Thousand Oaks, New Delhi: Sage Publications in association with The Open University.

[8]. Jessup, Helen. (1989). Netherlands Architecture in Indonesia, 1900 - 1942 [2 volumes]. Ph.D. Dissertation, Courtauld Institute of Art, University of London.

[9]. Keith, Michael \& Pile, Steve (eds.). (1996). Place and The Politics of Identity. London and New York: Routledge.

[10]. Hall, Stuart. (1991). "Old and New Identities, Old and New Ethnicities," dalam King, Anthony D. (ed.). (1991). Culture Globalization and the World System: Contemporary Conditions for the Representation of Identity. Hampshire and London: Macmillan Press Ltd.

[11]. Kurniawan, K.R. (2013). The Hybrid Architecture of Colonial Tin Mining Town of Muntok, with a Prologue by Budi Adelar Sukada. Jakarta: UI Press.

[12]. Kurniawan, K.R. (2014). Paradox: Sebuah Naratif Tentang Arsitektur dan Urbanisme di Indonesia Pasca Reformasi. Pidato Pengukuhan Guru Besar Arsitektur FTUI, 8 Oktober 2014, di Depok. Jakarta: UI Press.

[13]. Kusno, Abidin. (2000) Behind the Postcolonial: Architecture, Urban Space and Political Cultures in 
Indonesia. London and New York: Routledge.

[14]. Kusno, Abidin. (2011). '(Re-)Searching Post-Revolutionary Modernism: Indonesia after Decolonization', makalah disajikan dalam "Non-West Modernist Past" Conference, Singapore 15-16 January 2011, organized by AA Asia and Singapore Institute of Architects (SIA).

[15]. Lay, Cornelis. (2003). 'Otonomi Daerah dan Keindonesiaan' dalam A. Gaffar Karim (ed). Kompleksitas Persoalan Otonomi Daerah di Indonesia. Yogyakarta: Pustaka Pelajar dan Ilmu Pemerintahan, UGM.

[16]. Lefebvre, Henri. (1991). The Production of Space, translated by Donald Nicholson-Smith. Oxford UK \& Cambridge USA: Blackwell.

[17]. Partridge, Eric. (1983). Origins: A Short Etymological Dictionary of Modern English. New York: Greenwich House.

[18]. Pascher, Cor. (2007). 'Colonial architecture in Indonesia, References and developments' dalam Nas, Peter (ed). (2007). The Past in the Present: Contemporary Architecture in Indonesia. Rotterdam: NAl Press in association with KITLV Leiden.

[19]. Passcher, Cor. (2016). Building in Indonesia 1600 - 1960. Volendam: LM Publishers.

[20]. Sandercock, Leonie. (ed.), (1998). Making the Invisible Visible: $A$ Multicultural Planning History. Berkeley, Los Angeles, London: University of California Press.

[21]. Sudrajat, Iwan. (1991). A Study Of Indonesian Architectural History. A Thesis submitted in fulfilment of the requirements for the degree of Doctor of Philisophy at the Department of Architecture University of Sydney.

[22]. Widodo, Johannes. (2007) 'Modern Indonesian Architecture: Transplantation,Adaptation,Accommodati on and Hybridization' dalam Nas, Peter (ed). (2007). The Past in the Present: Contemporary Architecture in Indonesia. Rotterdam: NAl Press in association with KITLV Leiden.

Internet

[23]. Diela, Tabita. (2013). 'Arsitektur Betawi Bukan Identitas Jakarta?' Kompas.com. http://tekno.kompas.com/read/2013/06 /27/1556580/arsitektur.betawi.bukan.ident itas.jakarta (5 Agustus 2014).

[24]. Saieh, Nico. (2014). 'Craftsmanship: Material Consciousness - Inside
Indonesia's Pavilion at Venice Biennale 2014'.

Archdaily.

http://www.archdaily.com/

527548/craftsmanship-materialconsciousness-inside-indonesia-spavilion-at-venice-biennale-2014/ Agustus 2014).

[25]. Gunawan, Solichin. (2013). 'FATSUN (fatsoen) PROFESI...MASIH ADA YANG INGAT?' esubijono.wordpress.com. http://esubijono.wordpress.com/2013/03/0 6/peremajaan-bangunan-di-jakarta/ (9 Agustus 2014).

[26].......... (2015). 'Pesona Wisata Gorontalo Kantor Gorontalo'. Pesonawisataindonesia.com.

http://pesonawisataindonesia.com/pesona -wisata-gorontalo-kantor-gorontalo/ Desember 2017).

[27]. Wresti, M Clara dan Cahyaningrum, Siwi Yunita. (2016). 'Wae Rebo, Negeri Tersembunyi di Flores'. Kompas.com. http://regional.kompas.com/read/2016/11/ 05/11284481/wae.rebo.negeri.tersembun yi.di.flores?page=all (11 Desember 2017).

[28]. Sopandi, Setiadi. (2014). Pameran Sejarah. Konteks.org, http://konteks.org/pameran-sejarah $\quad$ (9 Agustus 2014).

[29]. Tjahjono, Gunawan. (2016). 'Guru Besar Arsitektur: Ada 5 Jenis Arsitek, Anda Masuk yang Mana?' Tempo.com. https://cantik.tempo.co/read/800847/gurubesar-arsitektur-ada-5-jenis-arsitek-andamasuk-yang-mana (19 Desember 2017). 